\title{
Dynamic model of wind energy conversión systems with variable speed synchronous generator and full-size power converter for large-scale power system stability studies
}

\author{
J.A. Sánchez , C. Veganzones , S. Martínez ，F. Blázquez , N. Herrero , J.R. Wilhelmi \\ Department of Civil Engineering: Hydraulics and Energy, ETSICCP, Universidad Politécnica de Madrid, Ciudad Universitaria, s/n. 28040 Madrid, Spain \\ Department of Electrical Engineering, ETSII, Universidad Politécnica de Madrid, C/José Gutiérrez Abascal, 2. 28006 Madrid, Spain
}

\begin{abstract}
This paper presents a dynamic model for variable speed wind energy conversión systems, equipped with a variable pitch wind turbine, a synchronous electrical generator, and a full power converter, specially developed for its use in power system stability studies involving large networks, with a high number of buses and a high level of wind generation penetration. The validity of the necessary simplifications has been contrasted against a detailed model that allows a thorough insight into the mechanical and electrical behavior of the system, and its interaction with the grid. The developed dynamic model has been implemented in a widely used power system dynamics simulation software, PSS/E, and its performance has been tested in a well-documented test power network.
\end{abstract}

Keywords: Modeling; Power system stability; Wind power generation

\section{Introduction}

Electrical energy production from renewable sources, and particularly wind power, is increasingly important in industrialized countries. Indeed, wind power is now a notso-small percentage of the power generation industry and it is rapidly becoming higher. With the massive penetration of wind energy conversión systems in the power network, some new problems arise, not only in technical áreas, but also in economy, policy and regulatory fields. The results presented in this paper are related to the development of new tools needed to face the technical problem of integrating a large number of wind generators (WGs) in the power grid.

Dynamic models for conventional generators and other power network components, and their corresponding control systems, are generally well described in the literature and known by power system engineers
However, WGs behave in different ways because of their differences in size, technology, and prime movers. Detailed models have been developed for the different technologies used in the megawatt class of WGs, mainly organized into four categories: squirrel-cage induction generator connected directly to the grid, wound-rotor induction generator with variable rotor resistance, doubly fed asynchronous generator, and synchronous or induction generator with full-size power converter . These detailed models are useful for a thorough insight into the mechanical and electrical behavior of the system and its interaction with the grid.

When studying the dynamic behavior of an electric power system with high wind generation penetration, the level of detail of the models used does not need to be so high. Furthermore, detailed models do not work well because of the high number of state variables and the small time constants involved. Thus, simplified models are used for representing WGs in power system dynamics simulations that facilitate the investigation of the impact of a large number of WGs on the behavior of a large power system 
This paper presents the development of a dynamic model, suitable for its use in power system stability studies involving large networks, with a high number of buses and a high level of wind generation penetration, for a type of variable speed wind energy conversión system not covered yet in the scientific literature: a variable pitch wind turbine (WT) with a synchronous electrical generator with wounded excitation, and a full power converter. The suitability of the model for this kind of studies has been demonstrated by means of its implementation in a widely used power system dynamics simulation software, PSS/E. The dynamic behavior of the model is compared with that of a detailed model of the same WG implemented in Matlab/Simulink , showing an adequate tracking of the relevant dynamics. Finally, the performance of the PSS/E implemented model is tested in a well-documented test network for dynamic studies

Besides, wind power plants are composed of a large number of few megawatt generators, linked together by a médium voltage network. Obviously, the dynamic behavior of such clusters does not fit well in the models of conventional generators, so reduced-order or aggregation models have been investigated An additional application of the model described in this paper is the assessment of aggregation models for this class of WGs.

The paper is organized as follows. Section 2 presents the developed model, based on the particular requirements of power system dynamics simulations. Section 3 compares the developed model with the detailed one, and Section 4 shows its performance in a test network when integrated in PSS/E.

\section{Model description}

The developed model is able to represent the transient performance of any wind energy conversión system belonging to the Variable Speed Wind Turbine Synchronous Generator System (VS-WTSG) family, as shown in Fig. 1.

The WT is composed of a rotor with three blades and, habitually, it has a pitch angle controller mechanism (PAC) to modify the blade pitch angle and, as a consequence, to limit the rotor speed and, obviously, the generated power at high wind speeds. The electrical generator unit (SG) can

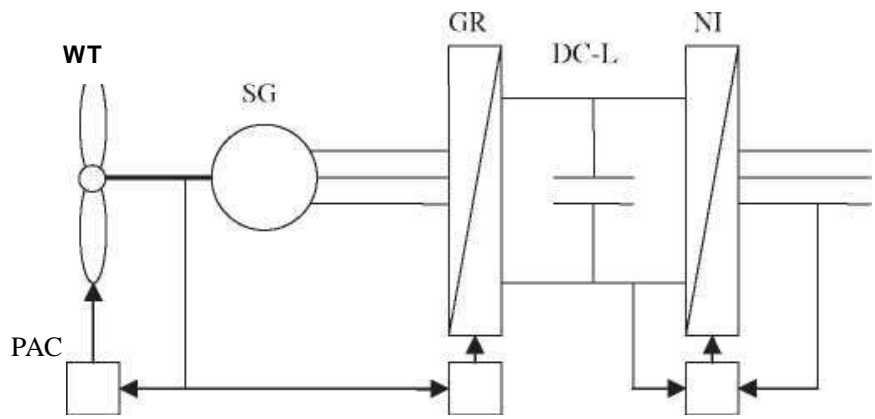

Fig. 1. General description of a VS-WTSG system. be of both, permanent magnet synchronous generator, or a wounded rotor synchronous generator. It can be a conventional SG with two or three pairs of salient poles and a gearbox to couple it to the WT, or a special multipole machine directly driven by the WT (no gearbox is needed).

An electronic power conditioner system (EPS) is needed to control the variable speed operation of the system. The EPS is composed by two electronic converters connected trough a de link: a generator side rectifier (GR) and a network side inverter (NI). GR must control the electromagnetic torque of the generator. It can consist of a diode rectifier and a boost converter, or of a voltage source converter. The NI must control the power injected to the grid, and it consists of a voltage source converter.

Fig. 2 shows the WT torque speed curves for several wind speed valúes. The torque-speed control strategy, usually followed in a VS-WTSG system, is also represented (thick line) . This control strategy is achieved through the coordinated action of the GR and the pitch angle WT controller (PAC), as it will be shown later. Three different regions can be distinguished in the curve that represents this control strategy: A, for low and médium winds, a máximum power tracking strategy is followed; B, médium wind speeds, the rotational speed must be maintained inside limits; $\mathrm{C}$, high wind speeds, both the rotational speed and the power must be maintained within limits.

Fig. 3 shows the general programming structure of the model, where the different simulation blocks are

- WT, wind turbine aerodynamics;

- PAC, pitch angle controller;

- DV, mechanical drive system;

- G-RECT, generator, rectifier, and the system that controls the torque of the generator;

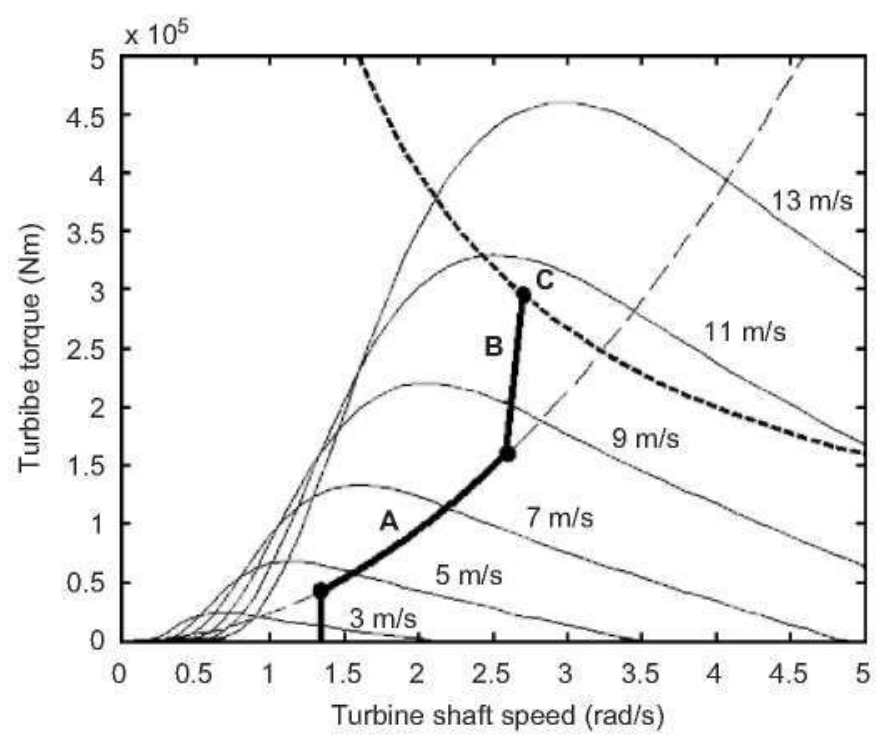

Fig. 2. Torque-speed curves and control strategy. 


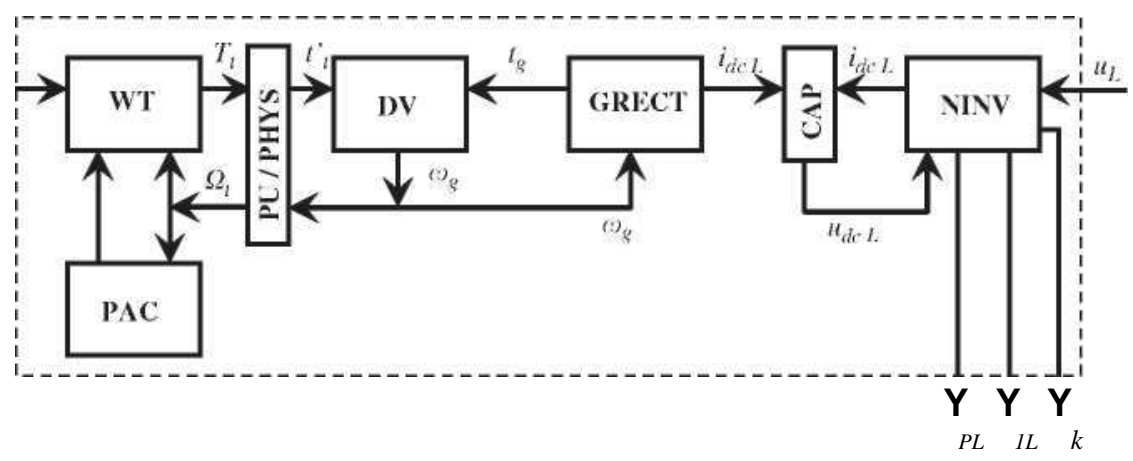

Fig. 3. General programming structure of the VS-WTSG model.

- N-INV, inverter, to control the power supplied to the network;

- CAP, de link capacitor; and

- PU/PHYS, per unit to physical quantities conversión.

To simúlate the operation and control of a VS-WTSG system, this model has been implemented in FORTRAN programming language. In this way, its incorporation in usual power system dynamics simulation software packages (for example, PSS/E) is simplified.

For the same reason, the variables and magnitudes used in aerodynamic bloek models (WT, PAC) are expressed in physical units, and the variables and magnitudes used in the other electrical (G-RECT, CAP, N-INV) and meehanieal (DV) bloek models are expressed in a per unit (p.u.) system. The connection between the two groups of programming blocks must be done using the PU/PHYS bloek to convert per unit valúes in physical valúes. Generator valúes at rated conditions have been chosen as base valúes for the p.u. system.

As can be seen in Fig. 3, the VS-WTSG model requires the wind speed, $V_{v}$, and the grid voltage phasor, $u_{L}$ (modulus and angle), as inputs. Wind speed is an external function, and grid voltage phasor is supplied by the network simulator. The model calculates, and supplies as outputs, the grid current phasor, $i_{L}$ (modulus and angle), and the active $/ ?_{\mathrm{L}}$, and reactive $\mathrm{g}_{\mathrm{L}}$, grid power.

The different parts of the model are described in the following sections.

\subsection{Wind turbine dynamics model}

The set of the WT and PAC blocks simulates the wind to meehanieal energy conversion that takes place in the WT, taking into account the pitch angle regulation. The wind speed, $\mathrm{F}_{\mathrm{v}}$, and the rotational speed, $Q_{t}$, are required as inputs, and the turbine torque, $T_{t}$, is supplied as output.

The WT simulation bloek in Fig. 3 evaluates the meehanieal torque produced by the wind, taking into account rotor blades geometry, wind speed, and rotational speed conditions. The following algebraic equation has been employed:

$T_{\mathrm{t}}\left(\Omega_{\mathrm{t}}, V_{\mathrm{v}}\right)=\frac{1}{2} \pi R^{2} \rho_{\mathrm{v}} \frac{V_{\mathrm{v}}^{3}}{\Omega_{\mathrm{t}}} C_{\mathrm{p}}(\lambda, \beta)$,

where $V_{v}$ is the wind speed, $Q_{t}$ the turbine rotational speed, $R$ the WT radius, $\mathrm{C}_{\mathrm{p}}$ the power coefficient, $\mathrm{p}_{\mathrm{v}}$ the air density, $i i$ the blade pitch angle and $X$ is the tip speed ratio.

Manufacturers usually give an experimental relationship between $\mathrm{C}_{\mathrm{p}}$ and $X$ parameters, for several valúes of the blade pitch angle $i$. In order to evalúate the $\mathrm{C}_{\mathrm{p}}$ coefficient, interpolation functions are used to approximate this experimental relationship, within each range of instantaneous valúes of $X$. From this process, the following expressions result:

$$
\begin{aligned}
& C_{\mathrm{p}}(i, \beta)=0.5\left[\frac{a(\beta)}{i}-b(\beta)\right] \mathrm{e}^{c(\beta) / \lambda}, \\
& 0<i<\lambda_{\max }(\beta),
\end{aligned}
$$

$$
\begin{aligned}
& C_{\mathrm{p}}(\lambda, \beta)=C_{\mathrm{p} \max }\left[1-\frac{\lambda-\lambda_{\max }(\beta)}{\lambda_{0}(\beta)-i_{\max }(\beta)}\right]^{2}, \\
& \lambda_{\max }(\beta)<i<\lambda_{0}(\beta),
\end{aligned}
$$

where for each $f_{i}, \mathrm{C}_{\mathrm{pmax}}\left(/\right.$ ?) is the máximum valué of $\mathrm{C}_{\mathrm{p}}$; $/ l_{\max }(\mathrm{jS})$ is the $X$ value for $\mathrm{C}_{\mathrm{pmax}} ; A o(P)$ is the $X$ limit valué above which $\mathrm{C}_{\mathrm{p}}$ is nuil; and $a, b$ and $c$ are jS-dependent coefficients.

It must be observed that, in the torque evaluation expression (1), $\mathrm{C}_{\mathrm{p}}$ coefficient depends on pitch angle $i$, and pitch angle controller bloek (PAC, in Fig. 3) can modify this angle dynamieally. Fig. 4 shows the bloek diagram of the PAC mechanism of the WT programmed in the model, where $K p \cdot p, \quad K^{\wedge}$ are the proportional and integral coefficients of PAC; $K p$ is a constant of the first order model of the actuator; $/ ?_{\max }, i 6_{\mathrm{m}} \mathrm{m}^{\text {are }}$ the limits of the pitch angle controller; and $\mathrm{I}^{3} \mathrm{i}_{\mathrm{im}}$ is the limit value of rotational speed. The speed variation of the $i i$ angle is limited to a valué of $5 \%$. 


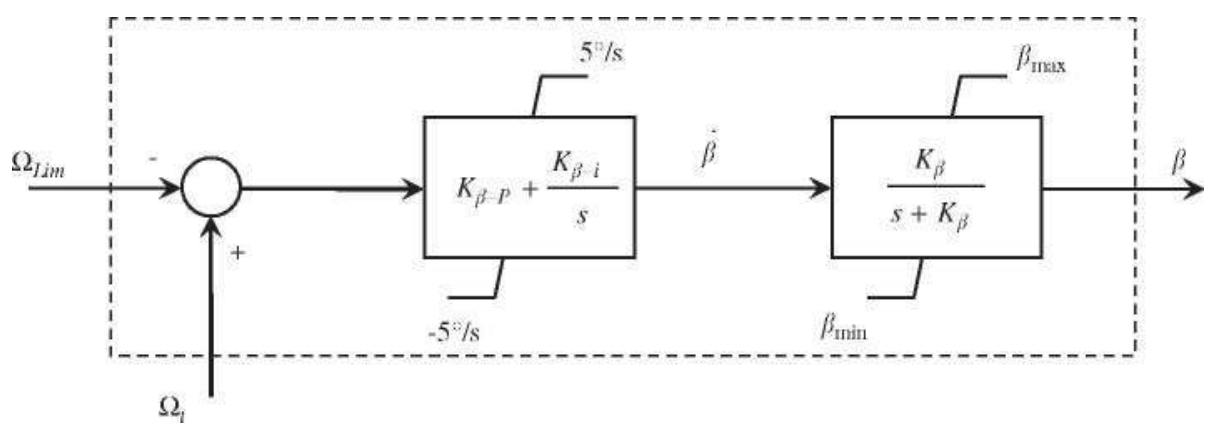

Fig. 4. Pitch angle controller system model.

\subsection{Drive train dynamics model}

The DV block represents this simulation component (see Fig. 3). This block evaluates the generator speed $\left(\mathrm{ffl}_{\mathrm{g}}\right)$, and requires as inputs the generator torque $(\mathrm{tg})$ and the turbine torque $(t[)$.

The dynamics of the drive train is represented by the classical rotational dynamics equation, where bearings and fan cooling friction have been considered. Total inertia is concentrated in one lumped mass including the contribution of blades, hub, generator rotor, low- and high-speed shafts and gearbox, if present. The motion dynamic equation of the drive system, formulated in per unit, has the following expression:

$\frac{\mathrm{d}\left(\omega_{\mathrm{g}}\right.}{\mathrm{d} t}=\frac{1}{2 H}\left(t_{\mathrm{t}}^{\prime}-t_{\mathrm{g}}-d \times \omega_{\mathrm{g}}\right)$,

where $t[$ is the p.u. turbine torque; $d$, the p.u. transmission damping coefficient; $H$, the p.u. lumped inertia system constant; $\mathrm{co}_{\mathrm{g}}$, the p.u. rotational speed; and $t_{g}$ is the p.u. generator torque. It can be observed that the p.u. valúes of turbine torque $\left(t\{)\right.$ and speed $\left(\mathrm{ffl}_{\mathrm{g}}\right)$, and the physical valúes $\left(T_{t}\right.$ and $Q_{t}$ ) supplied for the WT simulation block, are related by means of the gearbox ratio $\left(r_{\text {trans }}\right)$. This transformation is accomplished by the simulation block named PU/PHYS in Fig. 3.

\subsection{Generator-rectifier system dynamics model}

The block G-RECT simulates the operation of the electrical generation system and provides the generator torque $(t g)$ and the de link current (z'dc-g)- It requires the generator speed $\left(\mathrm{Co}_{\mathrm{g}}\right)$ as input variable (see Fig. 3). As it has been said, the generator-rectifier set regulates the electromagnetic torque of the electric machine in order to follow the desired control strategy for the operation points of the WTG system, which is presented in Fig. 2. In this block, the operations of the set generator-rectifier have been modeled together as one compact system, and the following assumptions have been introduced:

- The operation of the power electronic elements of the controlled rectifier is supposed to be ideal, so it operates with unity power factor.
- Electromagnetic transients in the stator, damper windings effeets and saturation effeets are neglected, as it is usually done in these kind of studies

- Flux is constant, and the dynamics of the excitation system and field circuit are neglected.

Under these conditions, the programming process follows the following two steps.

\subsubsection{Evaluation of the $i<_{c_{-} g}$ current}

First of all, it must be considered that the ideal operation of the rectifier and the invariability of the flux in the generator mean that the $\mathrm{zdc}-\mathrm{g}$ current is approximately proportional to the electromagnetic torque of the generator. Furthermore, the torque must be determined as a function of the shaft speed (fflg), in accordance with the system operation strategy shown in Fig. 2. Therefore, the speed (fflg) defines directly the $z^{\prime} d_{c-g}$ current, as well as the torque, according to the operation strategy curve.

Note that Fig. 2 shows that the mathematical relationship between torque (or de current) and shaft speed, in the control strategy curve, depends on the operation zone. If the system is working in zone $\mathrm{A}$, torque has a quadratic dependence on speed, and this dependence becomes linear if the operation point is in zone B. These relations formulated in p.u. system have the following expressions:

z'dc- $_{\mathrm{g}}\left(0-{ }^{\wedge} 2 \mathrm{Tfflg}\left(0 \quad\right.\right.$ for $\mathrm{ffl}_{\mathrm{g}}<0.98 \mathrm{xfflii}$ !

Zdc-g(0 - m-i(Og(i) - ¿ T f $^{\circ}$ r 0.98 x ffli $i_{m}<$ fflg <CüI

where $k_{2} r, m_{T}$ and $b_{T}$ are constants, and $\mathrm{ffl}_{\text {lim }}$ is the speed limit valué.

Note that, as it will be explained later in the description of the CAP block, the algorithms for evaluating the $z_{\mathrm{dc}}^{\prime}$. valué could be disabled, in order to protect the capacitor against a dangerous overvoltage.

\subsubsection{Evaluation of the electromagnetic torque $t_{g}$}

Since, in this p.u. system, torque and power have the same numeric valué, it is possible to evalúate the 
electromagnetic torque by means oí the electromagnetic power oí the generator. The expression is

íg $-P Q-{ }^{\wedge} \mathrm{dc}-\mathrm{g}^{\wedge} \mathrm{dc}$

where $u_{a c \cdot g}$ is the rectifier p.u. de voltage and $r_{s}$ is the p.u. resistance oí the stator plus the rectifier equivalent resistance. Note that the first term oí this equation evaluates the de link transferred power, and the second one evaluates the electric losses in the circuit.

Furthermore, the ideal operation oi the rectifier and the invariability oí the flux in the generator imply the identity between the numerical valué oí $u_{d c} \cdot g$ and $c o_{g}$. So, Eq. (7) can be expressed in a more convenient manner as

$$
\text { fflgZdc } \quad ; \text { is } ; \text { dc-g }
$$

\subsection{Network inverter dynamics model}

The block N-INV simulates the operation of the inverter. It evaluates the line current $\left(\mathrm{z}_{\mathrm{L}}^{\prime}\right)$ and the active $\left(\mathrm{p}_{\mathrm{L}}\right)$ and reactive $\left(\mathrm{g}_{\mathrm{L}}\right)$ grid transfer power. It requires the de link capacitor voltage $\left(u_{c}\right)$ and line voltage $\left(\mathrm{M}_{\mathrm{L}}\right)$ at the grid connection point (see Fig. 3). The transference to the grid of the active power generated by the WTG is controlled by the voltage level of the de link capacitor. Additionally, the inverter controls the transfer of reactive power from or to the WTG system. Fig. 5 shows a more detailed structure of this block, where the symbols not yet cited represent $\mathrm{w}_{\mathrm{c} \cdot \mathrm{re}} \mathrm{f}$, voltage capacitor reference valué; $\mathrm{iT}_{\mathrm{L}}-\mathrm{p}$, -KL-Í, proportional and integral coefficients of the inverter controller; /?L-ref, grid active power reference valué; $\mathrm{pf}_{\mathrm{re}} \mathrm{f}$, grid power factor reference valué; and ¿L-iim, grid line current limit valué.

As in the simulation of the generator rectifier, the operation of the power electronic elements of this inverter is supposed ideal. Thus, the simulation is performed in two steps.

In the first, the grid active power reference /?L-ref, is determined by a closed control loop over the dc-link capacitor voltage, $u_{c}$. In order to transfer to the grid all the active power generated by the WTG, the inverter must maintain the rated voltage in the capacitor. If the energy transferred to the grid is less than the energy from the de link, the capacitor voltage increases, while it is reduced in the opposite case (see Fig. 5).

In the second step, the evaluation of the current line and the active and reactive powers is performed. The current line can be evaluated from the grid voltage, the active power reference, and the grid power factor reference valúes

$* \mathbf{L}=\begin{gathered}\text { Ph-reí } \\ U_{L} \mathrm{X} \mathrm{pf_{ \text {ref } }}\end{gathered}$

If, as a result of this expression, the line current valué exceeds its limit, ¿L-ïm, the generated power $/ ?_{\mathrm{L}}$ must be limited, regardless of its reference valué, /?L-re f, ${ }^{\text {so }}$ that $\ddot{u}^{\text {ne }}$ current is kept limited to its máximum valué. Thus, if $i \mathrm{~L}^{\wedge} \dot{\mathrm{L}} \mathrm{Lim}$, then ${ }_{j} \mathrm{p}_{\mathrm{L}}={ }_{j} \mathrm{p}_{\mathrm{L} \cdot \mathrm{re}} \mathrm{f}$; while, if $\mathrm{z}_{\mathrm{L}}>\mathrm{Z}_{\mathrm{L}} \mathrm{i}_{\mathrm{im}}$, then the power must be recalculated as $/ ?_{\mathrm{L}}-{ }^{\mathrm{M}} \mathrm{L}{ }^{\mathrm{X}}{ }_{i \mathrm{~L}-\mathrm{max}}{ }^{\mathrm{x}} \mathrm{pf}_{\mathrm{re}} \mathrm{f}-$

Once grid active power has been calculated, reactive power, $\mathrm{g}_{\mathrm{L}}$, can be easily evaluated, through the grid power factor reference valué, $\mathrm{pf}_{\mathrm{re}} \mathrm{f}$ - And, finally, the current line phasor can be evaluated from the active and reactive power and the voltage phasor:

$-\mathrm{L}^{\sim} \underset{\sim}{\sim} \underset{\sim}{\sim j q}$

\subsection{Dc-link capacitor dynamics model}

The block CAP evaluates the de voltage at the capacitor termináis. It requires the dc-link current valué, in the rectifier side (z'dc-g), obtained through expressions (5) and (6), and in the inverter side ( $\mathrm{ddc}-\mathrm{O}$, evaluated as the quotient between the active power supplied to the grid and the capacitor voltage. The difference between the de current rectifier output side and the de current inverter input side is the charge current of the capacitor. To calcúlate the

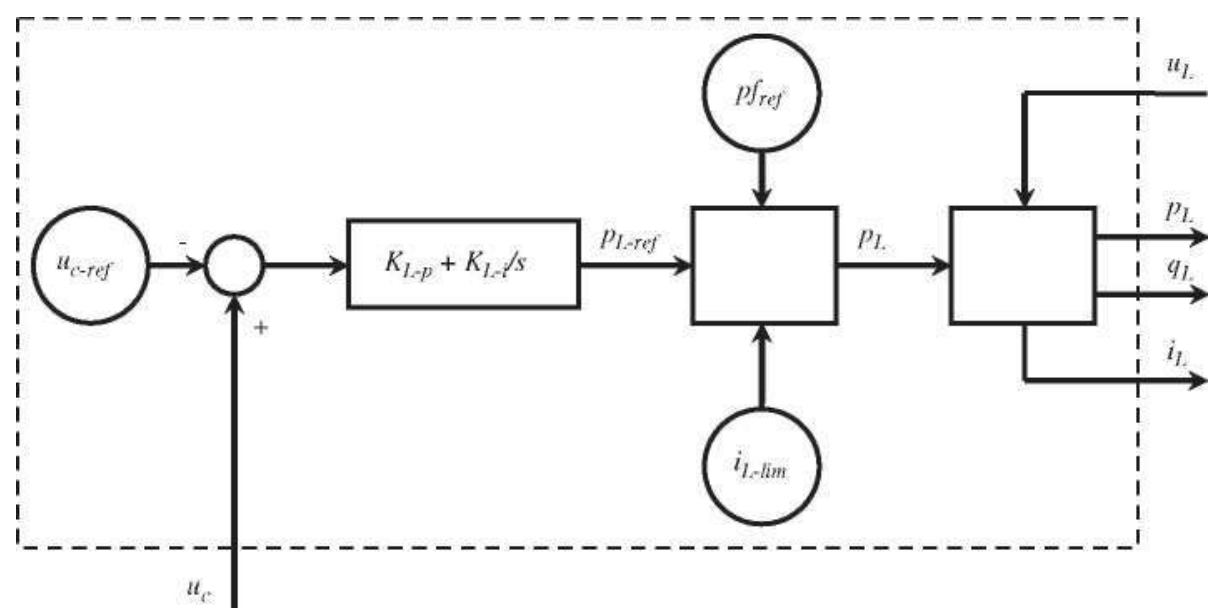

Fig. 5. Grid power control simulation block. 
capacitor voltage evolution, the following equation has been applied:

$\frac{\mathrm{d} u_{\mathrm{c}}}{\mathrm{d} t}=\frac{1}{C}\left(i_{\mathrm{dc}-\mathrm{g}}-i_{\mathrm{dc}-\mathrm{L}}\right)$.
Furthermore, this block must simúlate the change on the rectifier output current reference valué in some special circumstances. When the WTG supplies a certain amount of energy and the inverter can not transfer all this energy to the electrical network (i.e., in case of a voltage dip), the
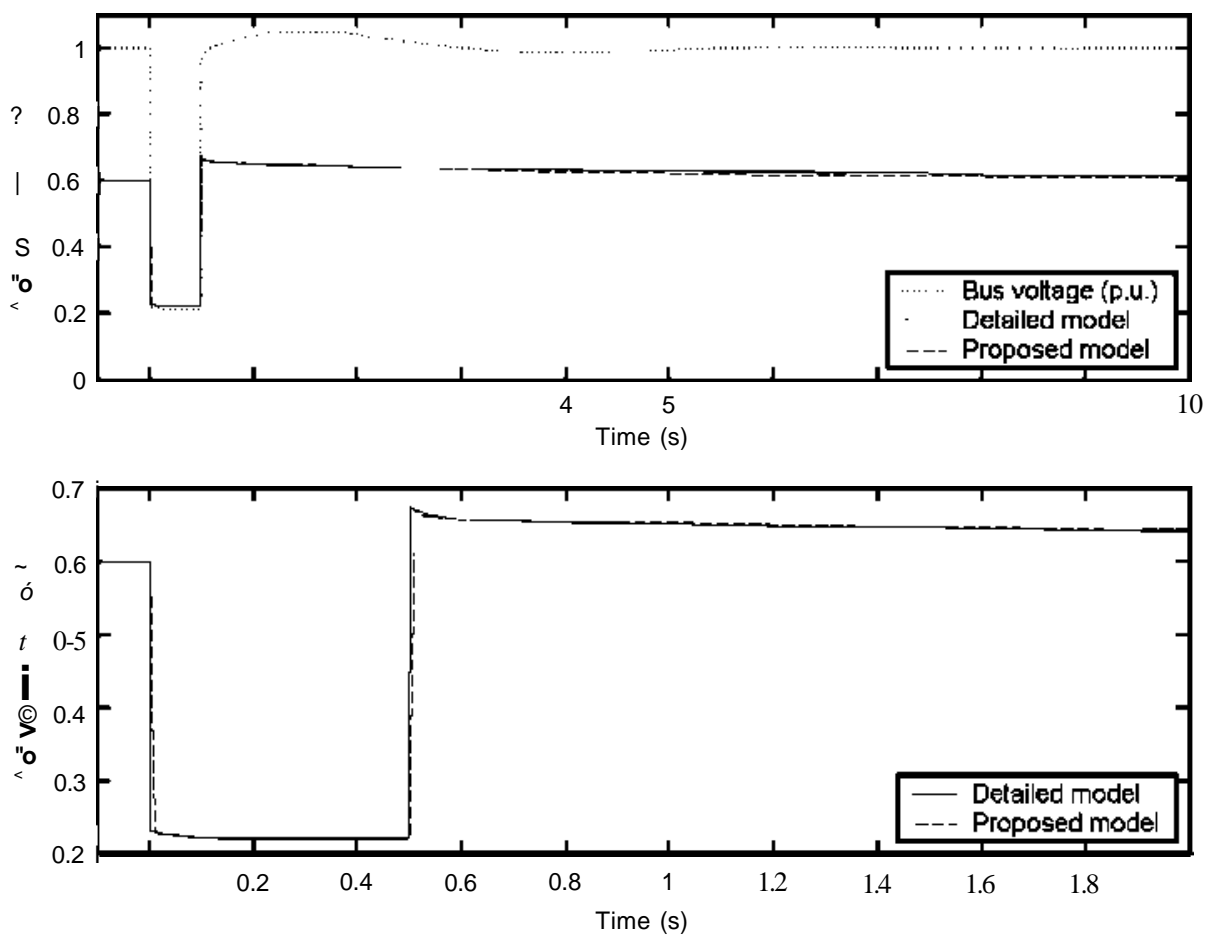

Fig. 6. Active power injected in the network by the wind generator, obtained from simulations with a detailed model (solid line) and with the proposed model (broken line).
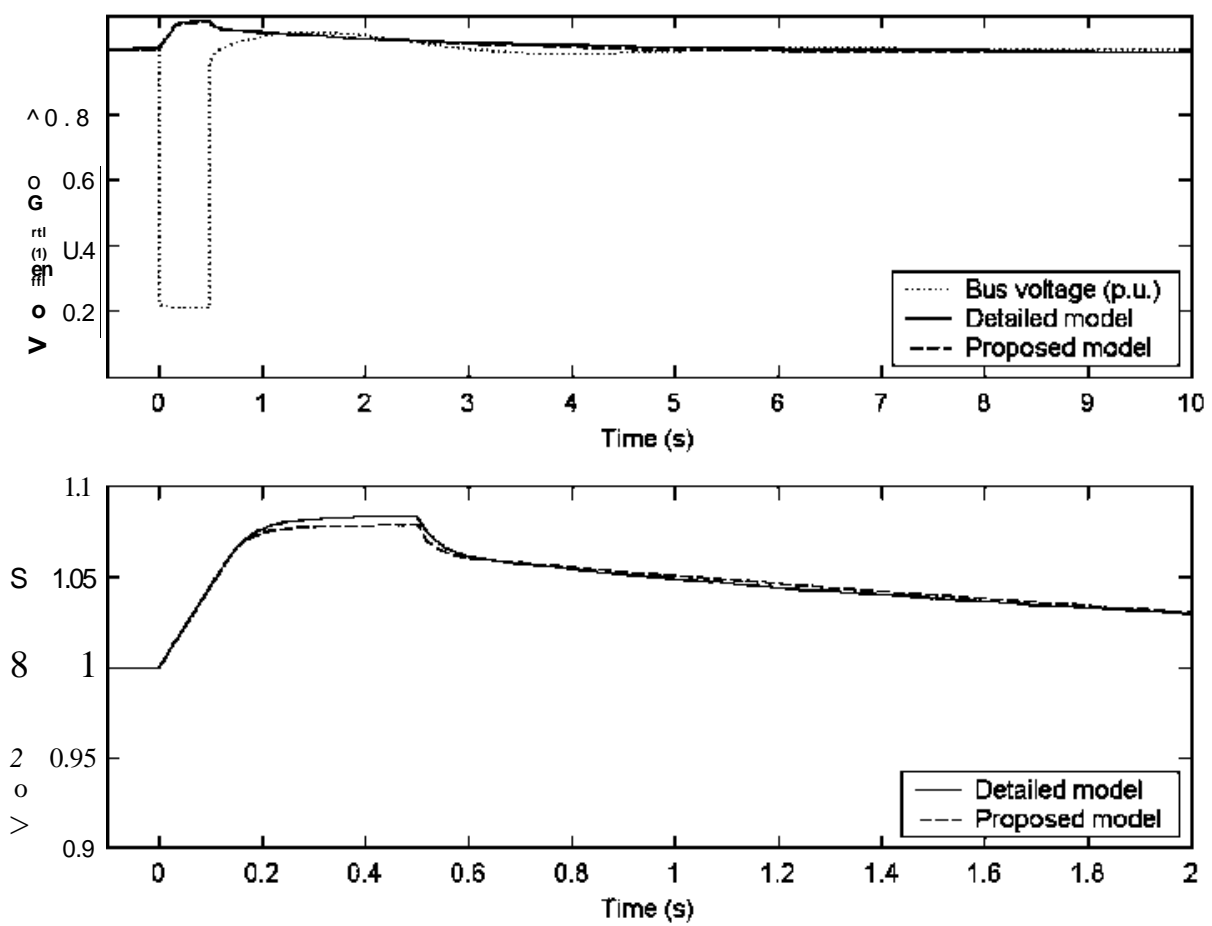

Fig. 7. Voltage in the de link, obtained from simulations with a detailed model (solid line) and with the proposed model (broken line) 
capacitor voltage increases, and, if the control strategy on the rectifier current output is not changed, the capacitor voltage limit could be exceeded, and the unit could be damaged. In this case, to protect the capacitor and to reduce the voltage at its termináis, the following control algorithm on the rectifier reference current, $/ /_{\mathrm{dc}} \cdot \mathrm{g}$, has been implemented:

$i_{\mathrm{dc}-\mathrm{g}}=i_{\mathrm{dc}-\mathrm{g}}-\frac{u_{\mathrm{c}}-\left(1+K_{\mathrm{u}}\right) u_{\mathrm{c}-\mathrm{ref}}}{u_{\mathrm{c}-\lim }-\left(1+K_{\mathrm{u}}\right) u_{\mathrm{c}-\mathrm{ref}}}$,

where $u_{\mathrm{c}-\mathrm{lim}}$ is the capacitor limit voltage and $K_{\mathrm{u}}$ is the p.u. allowable increment over $u_{\mathrm{c}-\text { ref }}$. This control algorithm is only activated when capacitor voltage goes beyond $\left(1+K_{\mathrm{u}}\right)$ times the rated voltage $u_{\mathrm{c}-\mathrm{ref}}$. So, a $K_{\mathrm{u}}$ band on $u_{\mathrm{c}}$ is allowed for the inverter control.

\section{Model validation}

The simplified model described in Section 2 has been validated by comparing its responses to various network disturbances with the corresponding ones of a detailed model of the same wind generation system. As an example, Figs. 6-8 show the time evolution of three magnitudes of a generator in a wind farm, following a short-circuit in a station cióse to the farm, cleared in $0.5 \mathrm{~s}$.

Fig. 6 presents the per unit voltage at the generator termináis along with the evolution of the active power injected to the network, simulated with both the detailed model and the simplified model proposed in this paper. The lower part of the figure shows with more detail the área of interest. As it can be seen, both results agree with great accuracy.
In a similar way, Fig. 7 shows the evolution of the voltage in the converter's de link, and Fig. 8 depiets the rotational speed of the generator.

\section{Model performance}

In order to verify the usefulness of the developed model, a study of its performance when integrated in a whole power system is needed. The IEEE Reliability Test System has been chosen to represent a complete power system due to several reasons: the number of buses (24) is high enough, the generating system contains 32 units and it includes the most important technologies (fossil oil steam, fossil coal steam, hydro and nuclear steam), there are two different voltage zones (138 and $230 \mathrm{kV}$ ) connected by transformers, the transmission system includes lines and cables, and voltage control devices (a synchronous condenser and a reactor) are present.

For connecting a wind plant (WP) in the IEEE Reliability Test System, a new bus (bus number 25) with other voltage level $(1 \mathrm{kV})$ has been introduced. This bus is

Table 1

PSS/E models for generators, governors, and excitation systems

\begin{tabular}{llll}
\hline \multirow{2}{*}{ Generation plant types } & \multicolumn{2}{l}{ PSS/E models } & \\
\cline { 2 - 4 } & Generator & Governor & Excitation system \\
\hline Hidro & Gensal & IEEEG2 & Sexs \\
Rest & Genrou & IEEEG1 & Sexs \\
\hline
\end{tabular}
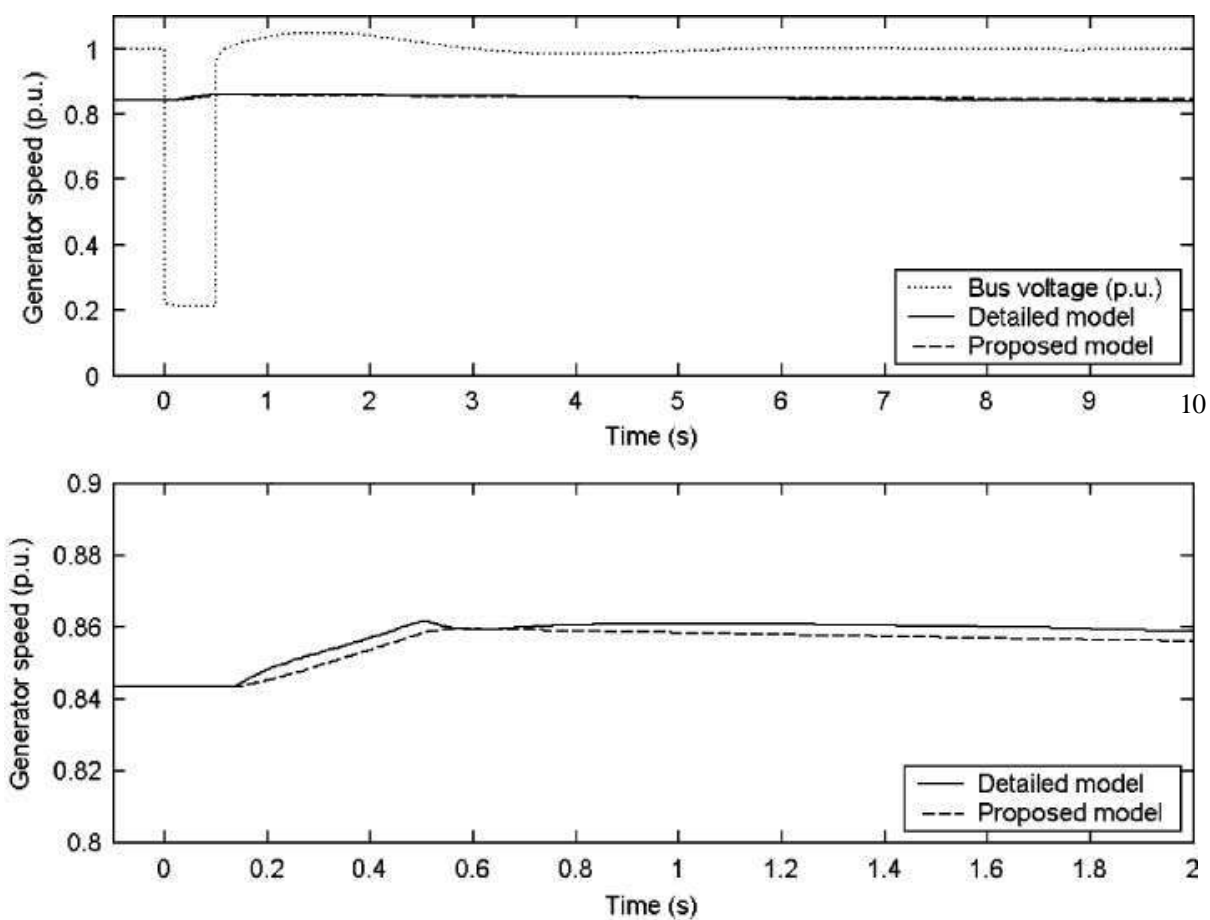

Fig. 8. Rotational speed of the generator, obtained from simulations with a detailed model (solid line) and with the proposed model (broken line). 
-'Vwv- IEEE RELIRBILITY TEST SYSTEM

cr

SHAH POWER
TECHNOLOGIES

FILE:

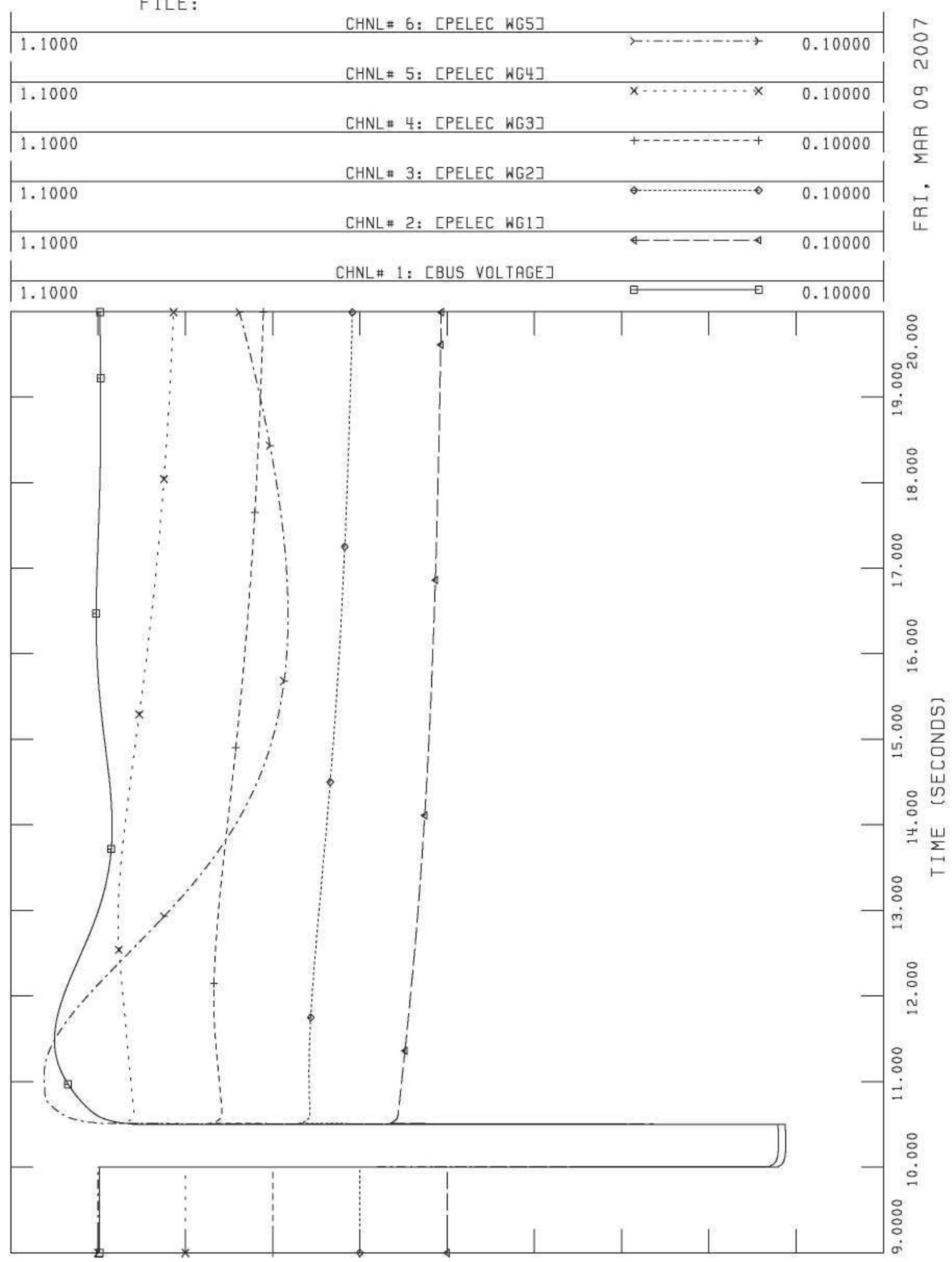

Fig. 9. Active power response. 
:EEE RELIHBILITY TEST SYSTEM

$\mathbf{t} \backslash \mathbf{I}$

5HRH FDHEñ
TECHNOLOGIE5
INC.@

FILE.

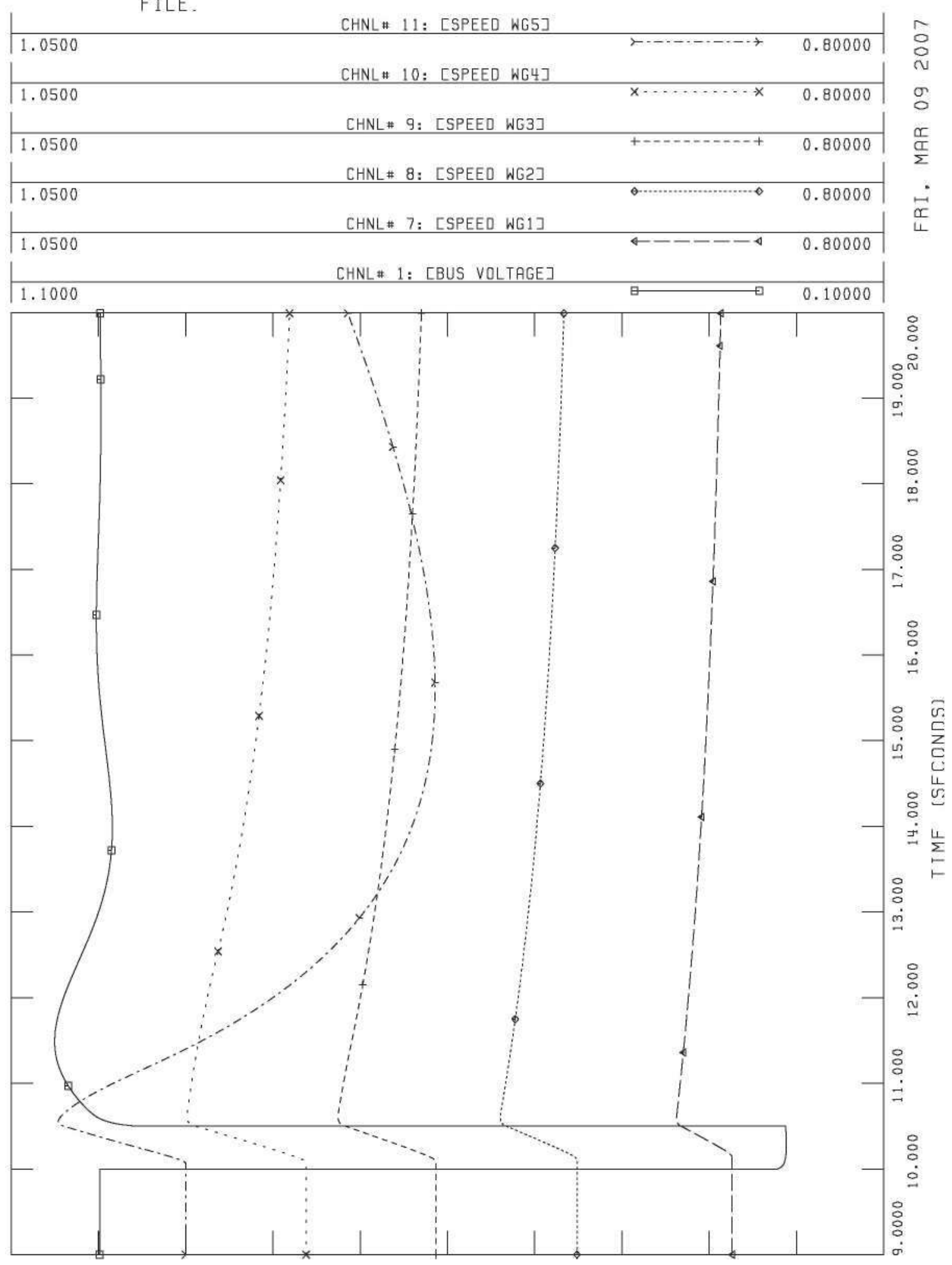

Fig. 10. WGs' speed response. 
ieEe Relihbitity test System

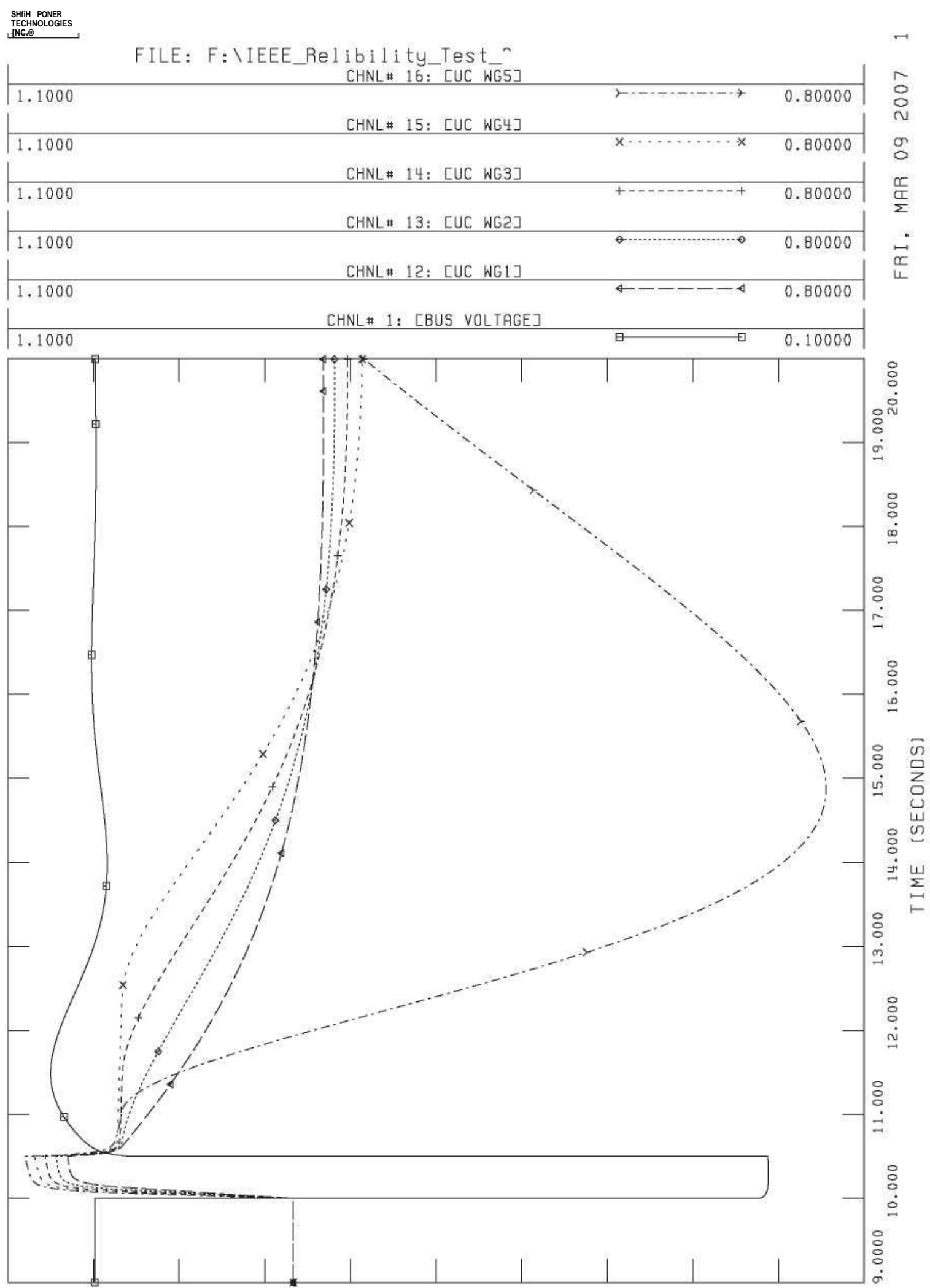

Fig. 11. Voltage level of de link. 
$-{ }^{*}|j| A^{*}>-\quad$ IEEE RELIHBILITY TEST SYSTEM $\quad$ or

SHHW POWER
rECHNDLOGIES
INCSTi

FILE: F: \IEEE_ReIibility_Test_Sys

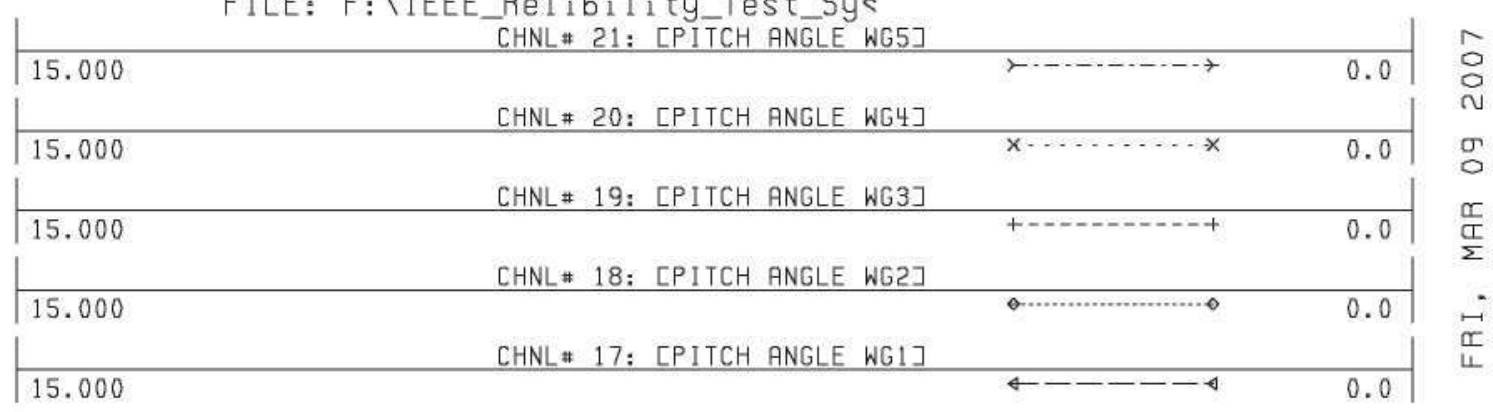

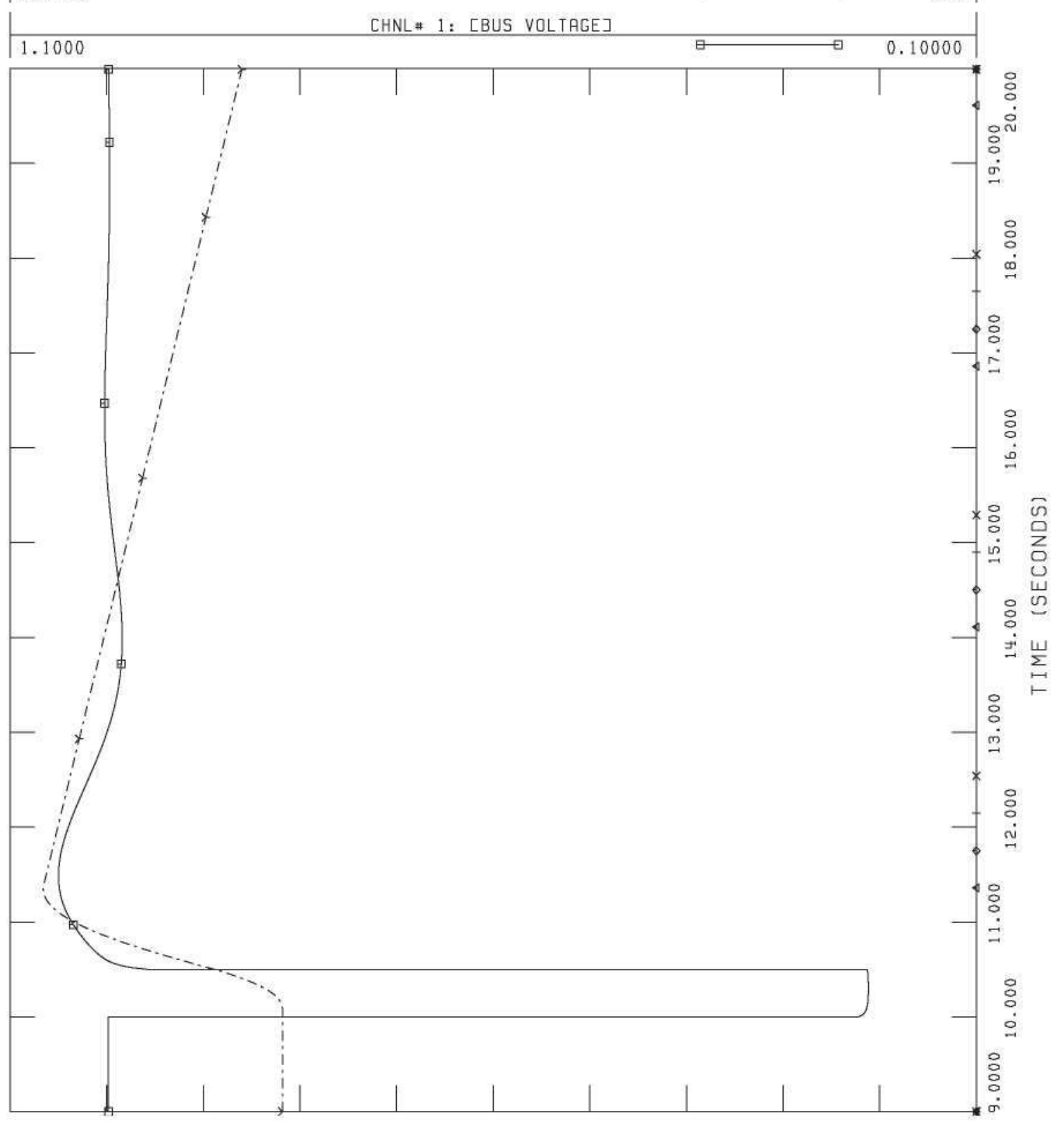

Fig. 12. Pitch angle. 
Table 2

Case study simulation parameters and simulation time

\begin{tabular}{llllll}
\hline & CON & STATE & VAR & ICÓN & ms/s \\
\hline Without WP & 1230 & 438 & 60 & 0 & 15 \\
With WP & 2230 & 638 & 60 & 40 & 25
\end{tabular}

joined to bus number 8 by a power transformer. The implemented WP is composed by 40 identical WGs oí $1 \mathrm{MW}$ rated power.

The whole system has been implemented in the widely used power system dynamics simulation software, PSS/E. For simulating the 32 generators of the IEEE Reliability Test System, several models supported by PSS/E software have been used. Table 1 shows these models for generators, governors, and excitation systems. The parameters of these models have been obtained from typical data of generation plants

Each WG has been represented with the dynamic model described in Section 2. This model introduces five new state variables in the simulation (a total of 200 new state variables).

The response of the proposed model to several network disturbances has been analyzed. As an example, results corresponding to a voltage sag to $20 \%$ are presented. In Fig. 9, the electrical power generated by five WGs is shown. Due to the different wind speeds, each WG was generating at a different power level previously to the voltage sag. During the disturbance, all WGs genérate the same electrical power because the current is limited by the inverter. So, the total power of the wind cannot be transmitted to the network. For this reason, part of this power is stored as kinetic energy, increasing WGs' rotational speed (Fig. 10). And the other part of the wind power is stored as electrostatic energy, increasing the voltage level of the capacitors (Fig. 11). When the voltage sag finishes, the WGs' speed, capacitor voltage and generated electrical power slowly return to their initial valúes.

As $\mathrm{WG}$ no. 5 is generating at rated power, the pitch angle control is always active (Fig. 12). So, this control affects the transient response of all variables of this WG.

In addition, to verify the developed model response, it is necessary to evalúate the viability of its use in a real network. The developed model must not introduce an increase in the simulation time greater than the one introduced by commercial PSS/E models. In order to confirm this point, two simulations have been made, one with a WP and another without a WP. Table 2 shows the number of simulation parameters and simulation time in both cases. As it can be seen, the increase in the simulation time (expressed as the ratio between time of program execution and real time) is not too high. Therefore, the developed model could be used in networks with a high number of buses.

\section{Conclusions}

A new computer model of a variable speed WT with a synchronous generator has been presented in this paper. This model has been developed with the aim of integrating it in power system stability software packages. Thus, the transient performance of these WT and their impact on the electric network can be analyzed.

The reliability of the model has been validated, comparing it with a much more detailed model of the same WTG technology, but too much complicated to be useful for the claimed goal. The transient performance of a $1 \mathrm{MW}$ WTG during a network deep voltage sag has been simulated with both models. The comparison of these simulations shows a good agreement, what supports the reliability of the model.

Finally, using this model, $40 \mathrm{WTG}$ units of $1 \mathrm{MW}$, have been integrated in the 24 buses, and 33 synchronous generators, IEEE Reliability Test System, previously implemented in the PSS/E software package. Transient response of the complete electric power system (including the 40 WTG), during a short circuit fault and its clearing, has been simulated. The increase in computer time due to the addition of these $40 \mathrm{WTG}$ to the existing 33 conventional units is only $66 \%$. So, the usefulness of the developed model has been shown.

\section{References}

Zavadil R, Miller N, Ellis A, Muljadi E. Making connections [wind generation facilities]. IEEE Power Energy Mag 2005;3:26-37.

DeMeo EA, Grant W, Milligan MR, Schuerger MJ. Wind plant integration [wind power plants]. IEEE Power Energy Mag 2005;3:38-46.

Piwko R, Osborn D, Gramlich R, Jordán G, Hawkins D, Porter K. Wind energy delivery issues [transmission planning and competitive electricity market operation]. IEEE Power Energy Mag 2005;3:47-56. Ahlstrom M, Jones L, Zavadil R, Grant W. The future of wind forecasting and utility operations. IEEE Power Energy Mag 2005;3:57-64.

Eriksen PB, Ackermann T, Abildgaard H, Smith P, Winter W, Rodríguez JM. System operation with high wind penetration. IEEE Power Energy Mag 2005;3:65-74.

Kundur P. Power system stability and control. New York: McGrawHill; 1994.

Anderson PM, Fouad AA. Power system control and stability. Piscataway, NJ: IEEE Press, Wiley-Interscience; 2003.

Heier S. Grid integration of wind energy conversión systems. Chichester, UK: Wiley; 1998.

Slootweg JG, de Haan SWH, Polinder H, Kling WL. General model for representing variable speed wind turbines in power system dynamics simulations. IEEE Trans Power Syst 2003;18(1): 144-51.

Herrero N, Veganzones C, Sánchez JA, Martínez S, Wilhelmi JR. Response of a variable speed synchronous wind generator to voltage dips. In: Proceedings of the 2004 international conference on electrical machines, Cracow, Poland, September 2004.

Albrecht PF, Bhavaraju MP, Biggerstaff BE, Billinton R, Elsoe Jorgensen G, Reppen ND, et al. IEEE Reliability Test System. IEEE Trans Power Apparatus Syst 1979;98(6):2047-54.

Castro RMG, Ferreira de Jesús JM. A wind park reduced-order model using singular perturbations theory. IEEE Trans Energy Convers 1996;11(4):735-41. 
Slootweg JG, de Haan SWH, Polinder H, Kling WL. Aggregated modeling of wind parks with variable speed wind turbines in power system dynamics simulations. In: Proceedings of the 14 th power systems computation conference, Sevilla, Spain, June 2002.

Castro RMG, Ferreira de Jesús JM. An aggregated wind park model. In: Proceedings of the 13th PSCC power systems computation conference, vol. 2, Trondheim, Norway, June-July 1999, p. 1302-7. Akhmatov V, Knudsen H. An aggregate model of a grid-connected, large-scale, offshore wind farm for power stability investigationsimportance of windmill mechanical system. Int $\mathrm{J}$ Electric Power Energy Syst 2002;24(9):709-17.
Slootweg JG, Kling WL. Modeling of large wind farms in power system simulations. In: Proceedings of the IEEE PES summer meeting, Chicago, July 2002.

Slootweg JG, Kling WL. Aggregated modelling of wind parks in power system dynamics simulations. In: Proceedings of the IEEE powertech conference, Bologna, Italy, June 2003.

Chinchilla M, Arnaltes S, Burgos JC. Control of permanent-magnet generators applied to variable speed wind energy systems connected to the grid. IEEE Trans Energy Convers 2006;21(1): 130-5.

Muljadi E, Butterfield CP. Pitch-controlled variable-speed wind turbine generation. IEEE Trans Ind Appl 2001;37:240-6.

PSS/E Program operation manual. Power Technologies Inc., 2004. 